\title{
Use of Unmanned Aerial Vehicles for Efficient Beach Litter Monitoring
}

Cecilia Martin ${ }^{\mathrm{a}^{*}}$, Stephen Parkes ${ }^{\mathrm{b}}$, Qiannan Zhang ${ }^{\mathrm{c}}$, Xiangliang Zhang ${ }^{\mathrm{c}}$, Matthew F. McCabe and Carlos M. Duarte ${ }^{\mathrm{a}}$

a. King Abdullah University of Science and Technology (KAUST), Red Sea Research Center (RSRC), Thuwal, 23955-6900, Saudi Arabia

b. King Abdullah University of Science and Technology (KAUST), Water Desalination and Reuse Center (WDRC), Thuwal, 23955-6900, Saudi Arabia

c. King Abdullah University of Science and Technology (KAUST), Computer, Electrical and Mathematical Sciences and Engineering Division, Thuwal, 23955-6900, Saudi Arabia

*Corresponding author email: cecilia.martin@kaust.edu.sa 


\begin{abstract}
A global beach litter assessment is challenged by use of low-efficiency methodologies and incomparable protocols that impede data integration and acquisition at a national scale. The implementation of an objective, reproducible and efficient approach is therefore required. Here we show the application of a remote sensing based methodology using a test beach located on the Saudi Arabian Red Sea coastline. Litter was recorded via image acquisition from an Unmanned Aerial Vehicle, while an automatic processing of the high volume of imagery was developed through machine learning, employed for debris detection and classification in three categories. Application of the method resulted in an almost 40 times faster beach coverage when compared to a standard visual-census approach. While the machine learning tool faced some challenges in correctly detecting objects of interest, first classification results are promising and motivate efforts to further develop the technique and implement it at much larger scales.
\end{abstract}

Keywords: Marine debris, Plastic pollution, Coastline, UAV, Machine Learning 


\section{Introduction}

Marine litter is defined as any persistent, manufactured or processed solid material discarded, disposed of, abandoned or lost in the marine and coastal environment [1]. Estimates report that $60-80 \%$ of macro-marine litter and up to $100 \%$ of all buoyant debris are derived from plastic [2, 3], although these represent only $16 \%$ of the worldwide municipal waste [4]. The reason for its prevalence is its light weight, buoyancy and durability, which make it easily transported by winds and currents and persistent in the ocean.

Recent evidence that marine plastic pollution is a ubiquitous and everlasting threat impacting on marine life $[5,6]$ has raised public awareness and catalyzed research efforts to quantify loads of plastic in the marine environment and consequently inform on mitigating measures $[7,8]$. The importance of resolving the mass balance and fate of marine plastic has also been highlighted by the finding that the global stocks of floating plastic represent only a minor proportion of all plastic ever discarded [9-12]. The burning question is where the larger stock of plastic entering the ocean is to be found. Four major sinks of plastic debris have been identified worldwide: fragmentation [9, 13-15], ingestion by marine life [16], sedimentation [17] and shore deposition $[3,5,18,19]$. Potentially, any coast or beach in the world could be reached by a floating item [20]. Therefore, marine debris (mainly plastic [21]), are found on shores regardless of their remoteness and proximity to human settlements [2, 22-25]. Moreover, beach litter is of particular concern because of the risk it represents for environment, health, society and the economy [26].

Beach litter may represent a terminal phase of oceanic transport or may represent a transient storage, with some deposits washed again to sea following severe storms $[19,27,28]$. In any case, beach cast litter constitutes an important stock, which needs to be accounted for 
when attempting mass balances of plastic entering the marine environment. Whereas progress has been made in estimating both global input rates [11] and global stocks and distribution of floating plastic $[9,10,12]$, estimates of the abundance and distribution of beach litter stocks, although numerous, are typically pursued on local or regional scales only (e.g. [25, 29-37] see also Table 2.1 in [3]) and are therefore insufficient to attempt a global inventory. In addition, despite the availability of guidelines to monitor beach litter (e.g. AMDS, NMDMP, NOWPAP and OSPAR guidelines; [38-41]), protocols differ, making comparison and integration of data challenging [3]. Most importantly, assessment of beach litter is time consuming [42]. Traditional beach monitoring relies on visual census methods, where plastic items are recorded along transects. According to OSPAR 2010 recommendations, plastic should be counted between the end of the beach and the water's edge along $100 \mathrm{~m}$ transects $(1000 \mathrm{~m}$ for items larger than 50 $\mathrm{cm})$. Litter items larger than $2.5 \mathrm{~cm}$ are collected, separated in classes and quantitatively measured. The whole process generally requires $2-5$ trained persons and ideally should take less than 3 hours per assessment $[37,38]$. Detection ability varies depending on the observer's skills, adding discrepancies to surveys carried out by different people [43]. Hence, visual censuses are subjective, time and labor consuming, and the area covered is in most cases only a sub-sample of the targeted beach. The median area surveyed across a number of studies $[25,31,32,35,36,42$, 44, 45] was 1.162 ha, ranging from 0.131 to 15.915 ha. Therefore, efficient acquisition of estimates of beach litter remains a major bottle neck to produce the data necessary to assess global distribution patterns, stocks, and contribution to regional and global marine litter mass balances.

Here we develop a more efficient method to assess marine beach litter loads involving the use of an Unmanned Aerial Vehicle (UAV) to record marine litter through image acquisition. 
We also provide evidence that the higher throughput of images delivered by the UAV's, which might also represent a bottle neck in terms of observer time, can also be greatly reduced by developing machine learning tools to expedite processing of the images acquired with the UAV, with the ultimate aim of quantifying and categorizing beach litter. Most importantly, this approach requires only one trained person and allows a total coverage of the beach in a few minutes.

UAVs, because of their high-resolution and their relatively low cost, are becoming useful and widespread tools supporting environmental and wildlife surveys [46-52], including monitoring coastal ecosystems to assess beach erosion, post-storm effects and anthropological impacts [53-55], amongst many other variables. The UAV market offers models below \$1000 which are suitable for a range of applications, rendering them as a cost-effective technique. Likewise, machine learning, through a range of increasingly powerful techniques, are being used to solve recognition and classification problems across a range of environmental and ecological research, from modeling species distribution, diversity and community composition to predicting forests fires and tsunamis [56-60]. While it is not our aim here to develop an efficient machine learning tool for this application, we do explore the viability of this approach and present some encouraging initial results, providing evidence that this is a feasible goal that should be developed further.

\section{Materials \& methods}

We develop and demonstrate a method for the assessment of beach litter using a quadcopter. UAV images were processed automatically, applying a beta version of the machine learning tool as a demonstration of the feasibility of the method. Comparisons with a standard 
visual census approach and manual processing of aerial pictures were conducted to assess the efficiency and accuracy of the proposed methodology. Here we report results from one test beach, supporting particularly high loads of beach litter over an extended area. The case study is located on the northern Red Sea $\left(26.9109^{\circ} \mathrm{N} 36.0077^{\circ} \mathrm{E}\right)$ and is described by an approximately $350 \mathrm{~m}$ long beach on a sandy shore, with small sparse bushes as vegetation and a NW exposure (Fig. 1). The closest human settlement is $4 \mathrm{~km}$ to the south, consisting of a dozen buildings and a small harbor.

\subsection{Remote survey}

The remote beach survey was performed using a DJI Phantom 3 Advanced (Adv) quadcopter (http://www.dji.com/phantom-3-adv) paired with a gimbal mounted 12 Mega Pixel camera. Weighing just under $1300 \mathrm{~g}$ and with a flight time of more than 20 minutes, the UAV is relatively lightweight remotely controlled system that has a range of up to $5 \mathrm{~km}$. The GPS/GLONASS positioning system allows a hover accuracy in the range of $0.5 \mathrm{~m}$ vertically and $1.5 \mathrm{~m}$ horizontally. Integrated safety and automated features such as beginner mode, auto-return home and visual and ultrasonic sensors allow a safe flight and recovery in case of mission failure. Battery, status and remaining power can be monitored in real time.

A preliminary test was conducted beforehand on a cleaned beach near the university facilities to select the best gimbal angle and altitude to perform beach surveys. Plastic items of different shape (bottles, bags, cups, bottle caps and food containers), color (transparent to brighter colors) and size (from $2 \mathrm{~cm}$ to $60 \mathrm{~cm}$ ) were arranged on the beach, both on a sandy and light background and on an organic matter and dark background. The system was flown at 5, 10 and $20 \mathrm{~m}$ altitudes above ground level (AGL), with the camera gimbal angled $45^{\circ}$ and $90^{\circ}$, with both video and still imagery collected. Camera settings were left in automatic mode. After 
analysis, the best approach that satisfied flight time, coverage, resolution and image quality resulted in a $10-\mathrm{m}$ altitude flight and $90^{\circ}$ gimbal angle. The relationship between flight altitude, image footprint and ground resolution for the Phantom $3 \mathrm{Adv}$ camera is shown in Fig. 2, where the ground resolution is based upon on a nadir pointing camera angle (i.e. $90^{\circ}$ to the ground). The chosen altitude is a good compromise between ground resolution, from 0.5 to $0.7 \mathrm{~cm}$ across and along track respectively, and footprint, $19.5 \mathrm{~m}$ across track, and it is preferred to the lower altitude for safety reasons (i.e. to avoid possible obstacles easily encountered in a 5-m flight). The $90^{\circ}$ gimbal angle allows a better recognition of item shapes, and stills are preferred to videos due to the lower data storage size and easier subsequent application of the automated machine learning based detection approaches.

Open UgCS v.2.10 was used to operate fully automated flight and navigation of the vehicle. Ground station software allow one to trace a flight route in transects upon placement of GPS waypoints on the targeted area map, allowing a total coverage of the beach. We used the Area Scan tool of Open UgCS v.2.10 for this purpose. Considering the remoteness of the test beach, we planned the mission on an offline map previously downloaded to overcome the need for internet connectivity at the sampled area. Automated flight with UgCS v.2.10 can be operated at a maximum distance of $500 \mathrm{~m}$. The UAV flight was planned to cover almost the entire length of the beach ( $325 \mathrm{~m}$ over $350 \mathrm{~m}$ of beach length) and a corridor 12 to $35 \mathrm{~m}$ wide from the water's edge. The UAV was flown at $2 \mathrm{~m} / \mathrm{s}$ at an altitude of $10 \mathrm{~m}$ AGL and stills were acquired automatically every $2 \mathrm{~s}$, allowing for a side overlap of approximately $10 \mathrm{~m}$, which assists in the post-processing alignment of imagery. The 243 acquired images (each $4000 * 3000$ pixels in size; i.e. 12MP) were processed using Agisoft PhotoScan Professional v.1.3.0, resulting in an orthomosaic of the area (Fig. 1). We used the same software to calculate area covered. The 
orthomosaic of the beach, was visually screened to count and classify anthropogenic debris in 10 categories, chosen based on the most common debris found during fieldwork and on their origin (i.e. sea-based and land-based activities), destination (e.g. food and drinks consumption, fishing, personal or household hygiene) and impact (e.g. presence of associated pollutants; Table 1, Fig. $3)$.

\subsection{Ground assessment}

A visual census composed of few short transects in the same areas surveyed with the UAV provides a necessary ground validation of the remote survey performance. To this end, we conducted a short transect (14 x $4 \mathrm{~m})$, where we manually counted and classified items in the same 10 categories identified above. We then compared visual census results with those obtained from visual screening through the aerial image of the same area (Fig. 4) to show how a field assessment can be used to correct the debris density estimation resulting from the proposed methodology.

\subsection{Feasibility of Developing a Machine learning tool}

For any future large-scale implantation of the approach, the high load of imagery obtained from the UAV demands a more automated analysis. Hence, we explored the feasibility of using machine learning to automatically detect and classify debris within the collected aerial images. Machine learning tools are able to identify and categorize objects once previously trained on selected imagery. To this end, we used images of known debris as training data, calculating their feature descriptors and then using them to train a classifier, thereby enabling the detection of targeted objects in previously "unseen" images.

Feature descriptors are used to describe image characteristics in vectors and thus allow their comparison, detection and classification. To depict the features of images used as training 
data, we employed a Histogram of oriented gradients (HoG) descriptor. The HoG is a classical and widely used feature representation method in the computer vision field, particularly successful in human face detection and pedestrian detection [61]. It counts the gradient orientation in a fixed-size part of the image and uses overlapping areas to make a normalization and therefore improves accuracy. The HoG descriptor consists of gradient computation, orientation binning, and descriptor block normalization. Usually, the descriptors are used to train a Support Vector Machine (SVM) classifier, which is popularly used for binary classification [62]. However, we used a random forest classifier due to its better performance on classification accuracy. The random forest algorithm is one of the more popular ensemble learning methods [63], which builds a number of decision trees as a forest from the training samples and uses the aggregated results from the set of decision trees to make predictions on testing samples. As one kind of ensemble classifier, random forest has the advantages of ensemble learning, high robustness and low generalization error. Randomness is introduced with the training subset selected randomly for each tree and feature subspace is provided randomly in the process of generating a tree. After the construction of the forest, the prediction can be made based on independent voting by each tree. The majority label of the voting is taken as the final prediction result. Therefore, interference between trees is reduced, effectively overcoming the overfitting problem of decision tree classifiers, and thus helping promoting the accuracy of classification, and also reducing the computational cost. Moreover, compared to SVM, random forest has good performance in high-dimensional data and multi-class classification [63], which is precisely what the proposed methodology is aiming at.

We developed a beta system based on the described machine learning approach and tested it on a subset of aerial pictures belonging to the case study beach. The beach was selected 
considering, among above cited features, the type of background, which should be relatively uniform to ease the classifier development (e.g. we excluded rocky sites, where rocks are easily wrongly detected by the random forest). Training samples for the classifier are obtained by clipping small fixed-size areas of $64 * 64$ pixels from the orthomosaic of the beach. This sample size showed a better performance than the alternatively tested $48 * 48$ pixels size given the characteristics of the objects of interest. Given the chosen size, the computed HoG descriptor is a vector of 1764 dimension. For better detection performances, we constructed three successive random forest classifiers with different training sets. The first two random forests are aimed at providing a binary classification of the image areas, with progressive filtering effect, into positive objects (i.e. litter) and negative objects (e.g., water, sand, bushes, wooden sticks, rocks), while the third classifier is designed to distinguish multi-class objects (i.e., drink containers, bottle caps, plastic bags). The training set is composed of positive and negative samples for the first two classifiers, where the positive were manually picked from the orthomosaic during visual screening as well as randomly generated, while negative samples were automatically cut from negative areas of the aerial pictures. In particular, we used 1125 and 1224 positive samples and 11509 and 4238 negative samples to train the first and the second classifiers respectively. The third classifier is trained on multi-class samples, with the goal of assigning objects to 3 categories: "drink containers" (including "drink bottles" and "drink drums"), "bottle caps" and "plastic bags" (Fig. 3a). Categories are selected a priori considering the most observed items during fieldwork and the more defined in terms of shape features, thus with potential to be rightly classified via machine learning. Multi-class training samples were obtained from the second random forest training set, including 1014 "drink containers", 88 "bottle caps" and 122 "plastic bags". To make classes of training data balanced, we randomly sampled $30 \%$ of the 
"drink containers" images $(\mathrm{n}=302)$ and generated triple times additive samples for "bottle caps" and "plastic bags" categories ( $\mathrm{n}=352$ and 488 , respectively) by small random floating in HoG descriptor. Negative samples were also included $(n=419)$ to reflect information of the background. The class weight is defined by a ratio of 1:1:1:1 after experiments. Other combinations of the number of samples and weights did not show obvious improvement or retrogress.

Testing aerial pictures are screened by the sliding window method, where HoG descriptor of the image area under the window is computed and decided by the random forests. Testing pictures are a subsample of the whole beach pictures $(n=13)$, chosen under the principle of more suspicious object and less influential background to demonstrate the applicability of the automated processing. For example, pictures with few objects in a complicated background are not picked, while those with many objects in a complicated background are still picked. Considering that adjacent aerial pictures have considerable within-image overlap, and that some of the pictures used for testing under the above principle may be adjacent, some objects may appear twice. Also, since chosen pictures are those with more objects, the results of the machine learning reported are to be used only as a comparison among methodologies and not as an estimate of litter density in the test beach. However, the results help in assessing the feasibility of developing efficient machine learning tools supporting the large-scale implementation of the drone-based assessments developed here, while providing clues to aspects of this methodology that are critical for successful machine learning applications.

\subsection{Visual census}

In parallel to the remote sensing based procedure and as a comparison with its timeefficiency, we conducted a standard visual census on 9 additional sites along the Red Sea 
coastline (Fig. 5), for a total of 93 transects (from 6 to 18 per beach). Sites were sandy beaches not influenced by human impact, and chosen depending on accessibility. Transects were randomly placed parallel to the coastline, just above the upper tidal limit. Their length varied from 5 to $50 \mathrm{~m}$ and were chosen dependently from items density: shorter lengths for highly dense spots and longer where items were sparsely scattered [34]. Transects width varied from 3 to $10 \mathrm{~m}$

and were chosen dependently from the beach width. For each transect we recorded GPS point, direction, time, number and type of objects and we took pictures of all items unless they were standard and common. Items were assigned to 10 categories (Fig. 3) as during visual screening of the orthomosaic.

\section{Results}

\subsection{Remote survey and manual screening of aerial pictures}

At the test beach, a 10-min flight allowed an area of approximately $6400 \mathrm{~m}^{2}$ to be covered. The visual screening of the orthomosaic took a few hours and reported a total of 1756 anthropogenic debris, yielding an average density of 0.27 items $/ \mathrm{m}^{2}$. The most abundant, excluding the category "others", were plastic bottles ( $\mathrm{n}=738,42 \%$ of total debris), followed by bags ( $\mathrm{n}=80)$ and bottle caps $(\mathrm{n}=46)$. Eighty-five items were directly related to fishing activities (4.8\% of total debris), including oil containers $(n=38)$, ropes $(n=24)$, polystyrene boxes and crates $(n=20)$, a buoy and two fishing nets. We also encountered 24 shoes, which we observed to be surprisingly common on Saudi beaches. Only 84 items were not plastic debris, and included glass bottles $(n=43)$, cans $(n=31)$, neon lamps $(n=8)$, a fridge and a washing machine (Table 2$)$.

\subsection{Ground assessment}


In the $56 \mathrm{~m}^{2}$ transect used as ground assessment, 123 items were detected through visual census, while manual screening of the UAV picture of the same area reported 76 items, thereby resulting in a $61.8 \%$ detection probability of litter identification from 10 m-altitude pictures compared to that derived using ground assessment. Item classification obtained from the two approaches is reported in Table 3. Items belonging to categories "oil containers" and "detergents and other liquids containers" were merged due to a missed distinction during visual census, while two of the 10 main categories of litter were not present in this area ("drink drums" and "boxes-crates-baskets"). Smaller items ( $<4 \mathrm{~cm}$ in average linear dimension) are those mainly not recorder through remote survey (e.g. small fragments, bottles caps, plastic rings, bullets, Table 3). Items with distinct shapes were easily recognizable (e.g. neon lamps and footwear) and were all detected with manual screening as well. Items belonging to the categories "drink bottles" and "oil containers and detergent containers" can easily be inappropriately classified with low resolution images due to their similar shape, which explains why items of the latter category detected with the remote sensing survey exceeded those counted with the visual census (Table 3). However, it is relevant to discriminate oil and detergent containers from drink bottles, despite their similar shape, because of their different pollutant profiles, which pose a major threat to the marine environment. Once we performed a chi-square test on the relative proportion of categories from the two approaches and considering visual census results as expected values, we determined that the distribution of the 7 main categories proportions were significantly different between methodologies $\left(X^{2}=17.09, \mathrm{df}=6, \mathrm{p}=0.009\right)$. However, this may be due to different abilities of the two procedures in detecting smaller items. Exclusion of small $(<4 \mathrm{~cm})$ items (i.e. bottle caps, rings, bullets and the straw) or exclusion of bottle caps only led to no significant 
differences in the distribution of other objects among categories $\left(X^{2}=10.06, \mathrm{df}=5, \mathrm{p}=0.0737\right.$ and $X^{2}=8.49, \mathrm{df}=5, \mathrm{p}=0.1312$, respectively).

\subsection{Machine learning}

Random forests applied on 13 testing aerial pictures reported a total of 2103 items (mean \pm SE $161.77 \pm 23.94$ per picture) divided into 1912 “drink containers", 120 "bottle caps" and 71 "plastic bags". The manual screening of the same 13 pictures instead outlined 413 items (31.77 \pm 5.69 per picture) belonging to the same categories: 367 "drink containers", 20 "bottle caps" and 26 "plastic bags". The 5-times larger number of objects identified automatically through machine learning is due to a tendency of false positives (i.e. natural items recognized as litter). Missed detections are also present (Fig. 6). However, there was a significant positive correlation between items abundance found with the two methodologies in each picture (Spearman correlation, $\mathrm{r}=0.61, \mathrm{p}=0.026, \mathrm{n}=13$ ), showing that images with higher density of plastic items lead to higher detections by the random forest algorithm. Moreover, the median relative proportion of the three categories obtained by the automated approach was $92 \%, 3.9 \%$ and $3 \%$ per picture for "drink containers", "bottle caps" and "plastic bags" respectively (mean $\pm \mathrm{SE}=91.4 \pm 0.8 \%, 4.5 \pm 0.8 \%$ and $4.1 \pm 0.8 \%$ ), which is comparable and not significantly different with medians found through manual screening of the same pictures: namely $88.1 \%, 4.9 \%$ and $6.8 \%$ (mean $\pm \mathrm{SE}=85.3 \pm 4 \%$, $4.5 \pm 1.1 \%$ and $10.2 \pm 3.3 \%$, Table 4$)$.

\subsection{Visual census}

The beach area covered through visual census accounted for $3956 \mathrm{~m}^{2}$ in 9 sites, excluding the transect for ground assessment of remote survey. The actual counting of debris along each transect took an average of 2-3 min, resulting in a time-efficiency of $16.31 \pm 1.3 \mathrm{~m}^{2} \cdot \mathrm{min}^{-1}$ (mean $\pm \mathrm{SE}$ ), from $1.25 \mathrm{~m}^{2} \cdot \mathrm{min}^{-1}$ to $30 \mathrm{~m}^{2} \cdot \mathrm{min}^{-1}$ in the most and least densely littered transects, 
respectively. Considering also the relocation between transects, which should be distant enough to have a good estimate of the entire beach, it took at least one hour to conduct a visual survey of 10 short transects $(10,15 \mathrm{~m}$ long) with two trained observers. In total, 1747 items were counted in all the 9 sites, yielding a total density of 0.44 items. $\mathrm{m}^{-2}$ and densities within transects ranging from 0 to 7 items. $\mathrm{m}^{-2}$ (mean $\pm \mathrm{SE}=0.63 \pm 0.1$ items. $\mathrm{m}^{-2}$ ) and within sites from $0.26 \pm 0.16$ to 1.72 \pm 2.66 items. $\mathrm{m}^{-2}$ (mean $\pm \mathrm{SE}=0.66 \pm 0.99$ items. $\mathrm{m}^{-2}$ ). Not surprisingly, the most abundant debris found were bottles ( $\mathrm{n}=723,41.4 \%$ of total litter; mean within sites $42.5 \pm 4.7 \%$ ), followed by oil containers ( $\mathrm{n}=162,9.3 \% ; 8.6 \pm 30.2 \%$ within sites). Non-plastic items, mainly glass bottles and jars $(\mathrm{n}=45)$, represent $5.72 \%$ of all debris $(\mathrm{n}=100,8.7 \pm 1.3 \%$ within sites, Table 5$)$.

\section{Discussion}

Saudi Arabian beaches are mainly remote and, except few cases, untouched by tourism or human activities, features that make them a good case study to determine dispersion of marine debris by natural and meteorological events. This analysis may require a seasonal monitoring of the beach, which is a major issue for an already time- and labor- consuming approach (such as the standard visual census). An efficient, reliable and accurate remote monitoring technique would make such a repeat survey far more feasible.

\subsection{The potential of UAV approaches for litter detection}

The beach survey conducted using a UAV resulted in a 39-time faster beach coverage than with a standard approach where a beach is screened by walking. Generally, the issue encountered during visual census of selecting easily accessible sites can be overcome through remote surveying, where areas can be easily monitored without direct access. The high footprint of the 
UAV allows one to cover almost the entire length of the beach, avoiding the need for random subsampling and providing a better and more reliable estimate of litter loads. The UAV survey was not limited to the beach as in standard approaches, but also included the back of the beach where plastic was also observed. Importantly, all of this coverage required the work of only one person. However, while remote surveys are undoubtedly highly time-efficient compared to visual approaches, this time-saving method may lead to loss in achievable accuracy.

Despite the high image resolution of less than $1 \mathrm{~cm}$, an underestimation of beach litter density obtained from aerial pictures compared to direct observation can be expected. Through manual screening of pictures, smaller items were often hardly detectable, and shadows, the presence of vegetation and discontinuous backgrounds (as well as the absence of a third dimension) sometimes complicated the recognition of larger items too. Through automatic processing of images, misdetections were mainly due to plastic items of small sizes $(<4 \mathrm{~cm})$ and the high variability of objects within the same category. Despite missing objects, random forest classifier actually overestimated litter abundance given false positives, mainly caused by a limited number of training samples, ambiguity of objects derived from limited image resolution and diffuse edges due to partial burial in sand, and backgrounds with reduced contrast with the objects. Nevertheless, both weaknesses, namely underestimation due to low resolution of aerial images and machine learning inaccuracy, can be minimized and addressed with future methodological implementations as following from the experience gained in this feasibility study.

\subsection{Methodological Improvements}

The use of ground controls is a valuable approach to correct the density underestimation. We showed an example of a visual transect in the beach case study. Although the total abundance of 
items in the area differs considerably between visual census and remote survey assessments, the relative proportion of debris categories is generally maintained, with the main differences encountered due to small debris. These results suggest that the remote sensing approach offers a practical methodology to classify beach litter, and if coupled with visual field assessments, to estimate its abundance too. For instance, litter density estimate obtained through remote survey and manual image processing accounted for 0.27 items. $\mathrm{m}^{-2}$, and detection accuracy compared to visual census was $61.8 \%$. Assuming this proportion to be representative, we could correct the underestimated density for a 1.62 factor and obtain a value of 0.44 items.m ${ }^{-2}$, which corresponds to the overall density found with visual census surveys. However, this requires additional field assessments of beaches surveyed using UAVs to obtain a robust empirical correction factor. Future UAVs flights should, therefore, be coupled with short visual transects.

Missing objects and false positives are common challenges when applying machine learning approaches. The inaccuracy of the automatic processing partly comes from high variability of both anthropogenic debris and background objects, which is not sufficiently represented in our training set due to the limited number of training samples, particularly for less abundant categories ("bottle caps" and "plastic bags"). Better performance can be achieved as the number of training samples derived from additional surveys increases. Also, a better classification execution can be obtained with higher resolution images (i.e. the Phantom 4 Pro offers a 20 MP camera). Higher image quality can also be obtained by conducting drone flights at $5 \mathrm{~m}$ height, when possible and, most importantly, after a thoroughly safety check on the irregularity of terrain altitude. Lower surveys imply a lower footprint, increased flight time and a higher imagery load, undermining the remote survey time-efficiency. However, efficiency would be anyway higher than with a visual census, while resolution would greatly improve, enhancing 
machine learning performances and shortening image processing times. The result is that the whole methodology (remote survey followed by automatic image processing) would maintain if not increase its efficiency. Moreover, the performance of machine learning approaches is expected to be enhanced by combination with deep leaning algorithms [64], where the features of objects are learnt and extracted by deep neuron networks rather than as pre-defined descriptors. The learned features will be more comprehensively expressive, and thus result in better detection and classification results. Meanwhile, the three-category recognition achieved by this first, exploration version of the machine learning tool provides a demonstration of the potential of an automatic approach. With improved performances, the classification could address more categories (e.g. Table 1) and yield more accurate estimates of litter density when applied to orthomosaics, devoid of within-image overlaps.

Although improvements can be accomplished, results obtained from the exploration "beta system" developed here clearly show the feasibility of using machine learning algorithms as an approach to assimilate the high-throughput of images resulting from the use of UAVs, where manual classification will be prohibitive in any regional-scale beach litter assessment. The relative abundance of objects as derived from the exploratory machine learning tool is comparable to a manual approach, while the correlation found between total counts within the two methods also demonstrates that a correction of the overestimation given by machine learning, even at this early demonstration stage, is possible.

\subsection{Towards a mass balance approach to litter estimation.}

One limitation of the proposed methodology is the lack of mass measurements, which are normally carried out during visual census, where debris are collected and weighed [38]. However, an estimate of the litter mass is still possible combining three approaches. First, 
common and standard items (e.g. oil containers, bottle caps and bottles of known volume) also have standard weights, so the mass estimates can easily be obtained by multiplication of their abundance and the average weight of few samples. Second, some objects have standard material composition (e.g. plastic bags, glass bottles, ropes, cans), so that knowing the density of the material, and inferring volume from object area, mass can be calculated. Object area can be gained automatically through random forest classifiers that can be computed to obtain area rather than abundance. Third, for any remaining objects (mainly plastic fragments), an estimation of density can be assumed considering mean density of floating plastic debris, which are more likely to reach beaches via water. A problem encountered in our methodology was related to the detection of smaller objects (i.e. likely to be missed), thus influencing density estimates - albeit with a lower impact on total mass, as these small items represent a modest contribution. Considering OSPAR guidelines, items smaller than $2.5 \mathrm{~cm}$, close to the threshold at which significant lack of detection occurs, are excluded from beach litter estimates through visual census, thus making our methodology consistent with current standards.

Importantly, visual census surveys described in this paper targeted different areas than that remotely monitored and were addressed in this analysis mainly to estimate visual census time-efficiency and make a comparison with remote surveys. However, the high agreement found between results from visual census and remote survey followed by manual screening is further evidence of the feasibility of using UAVs for beach surveys and allows to postulate specific hypotheses on the expected relative amount and typology of litter on Saudi Arabian beaches, where plastic bottles dominate.

Classifying as well as unveiling spatial and temporal patterns of marine litter in the Red Sea and globally is the key to identify its possible sources and sinks and help planning focused 
intervention: both preventive and restorative. The use of UAVs, coupled with efficient machine learning algorithms to process the large volumes of generated imagery, represent a promising approach to allow regional scale assessments of beach macro-litter and their assessment over time.

\section{Conclusion}

We compared the application of two methodologies to quantify beach litter: the standard visual census approach and a remote survey coupled with both manual and automatic recognition and classification. We showed how remote sensing via the use of an unmanned aerial vehicle can be a powerful tool to efficiently cover extended areas, while presenting as a feasible tool to estimate litter amount and state. We demonstrated that the machine learning based classification was concordant with two independent approaches (i.e. manual and automatic processing of UAV images), while the abundance over-estimations can be corrected for by algorithm improvements and iterations. Future perspectives associated with the proposed work will examine the implementation of the automated methodology following the suggested steps in order to obtain a product which can be successfully applied on a higher number of remote surveys, with the final aim of estimating beach litter density on a high spatial and temporal scale.

\section{Acknowledgments}

This work was supported and funded by King Abdullah University of Science and Technology (KAUST) through the baseline funding of CMD and by KAUST Office of Sponsored Research (OSR) under Award No. 2639. We thank the crew of $R / V$ Thuwal, the 
Coastal and Marine Resources Core Lab and Red Sea Research Center colleagues for field assistance. We particularly thank Mohammed Magbool Aljahdali, Núria Marbà and Dorte Krause-Jensen for support during field-work.

\section{Declarations of interest: none}

\section{References}

[1] UNEP, Marine litter: an analytical overview, UNEP, 2005.

[2] J.G.B. Derraik, The pollution of the marine environment by plastic debris: A review, Mar. Pollut. Bull. 44 (2002) 842-852. doi:10.1016/S0025-326X(02)00220-5.

[3] F. Galgani, G. Hanke, T. Maes, Global distribution, composition and abundance of marine litter, in: Mar. Anthropog. Litter, 2015: pp. 29-56. doi:10.1007/978-3-319-16510-3_2.

[4] S. Muenmee, W. Chiemchaisri, C. Chiemchaisri, Microbial consortium involving biological methane oxidation in relation to the biodegradation of waste plastics in a solid waste disposal open dump site, Int. Biodeterior. Biodegrad. 102 (2015) 172-181. doi:10.1016/j.ibiod.2015.03.015.

[5] J. Wang, Z. Tan, J. Peng, Q. Qiu, M. Li, The behaviors of microplastics in the marine environment, Mar. Environ. Res. 113 (2016) 7-17. doi:10.1016/j.marenvres.2015.10.014.

[6] T.S. Galloway, M. Cole, C. Lewis, Interactions of microplastic debris throughout the marine ecosystem, Nat. Ecol. Evol. 1 (2017). doi:10.1038/s41559-017-0116.

[7] D. Cressey, The Plastic Ocean, Nature. 536 (2016) 263. 
[8] D. Xanthos, T.R. Walker, International policies to reduce plastic marine pollution from single-use plastics (plastic bags and microbeads): A review, Mar. Pollut. Bull. 118 (2017) 17-26. doi:10.1016/j.marpolbul.2017.02.048.

[9] A. Cozar, F. Echevarria, J.I. Gonzalez-Gordillo, X. Irigoien, B. Ubeda, S. HernandezLeon, A.T. Palma, S. Navarro, J. Garcia-de-Lomas, A. Ruiz, M.L. Fernandez-de-Puelles, C.M. Duarte, Plastic debris in the open ocean, Proc. Natl. Acad. Sci. 111 (2014) 1023910244. doi:10.1073/pnas.1314705111.

[10] M. Eriksen, L.C.M. Lebreton, H.S. Carson, M. Thiel, C.J. Moore, J.C. Borerro, F. Galgani, P.G. Ryan, J. Reisser, Plastic Pollution in the World's Oceans: More than 5 Trillion Plastic Pieces Weighing over 250,000 Tons Afloat at Sea, PLoS One. 9 (2014). doi:10.1371/journal.pone.0111913.

[11] J.R. Jambeck, R. Geyer, C. Wilcox, T.R. Siegler, M. Perryman, A. Andrady, R. Narayan, K.L. Law, Plastic waste inputs from land into the ocean, Science (80-. ). 347 (2015) 768771. doi:10.1126/science.1260352.

[12] E. Van Sebille, C. Wilcox, L. Lebreton, N. Maximenko, B.D. Hardesty, J.A. Van Franeker, M. Eriksen, D. Siegel, F. Galgani, K.L. Law, A global inventory of small floating plastic debris, Environ. Res. Lett. 10 (2015). doi:10.1088/1748$9326 / 10 / 12 / 124006$.

[13] A.L. Andrady, I. Boustead, D.L.T. BEYNON, I. Hussain, H. Hamid, L.W. Hill, N.D. Searle, B. Smith, R.S.R. Murthy, Eunomia, F.J.M. Txn, G. Swift, J. Brandrup, M.M. Fisher, A.K. Gupta, D.G. Lilley, Y. Wang, Y. Zhang, M.B. Polk, S. Kumar, J.D. Muzzy, W. Lange, W. Hay, Plastics in the Marine Environment, 2005. 
doi:10.1177/0957926591002002007.

[14] A.L. Andrady, Microplastics in the marine environment, Mar. Pollut. Bull. 62 (2011) 1596-1605. doi:10.1016/j.marpolbul.2011.05.030.

[15] H.K. Webb, J. Arnott, R.J. Crawford, E.P. Ivanova, Plastic degradation and its environmental implications with special reference to poly(ethylene terephthalate), Polymers (Basel). 5 (2013) 1-18. doi:10.3390/polym5010001.

[16] P.G. Ryan, Ingestion of plastics by marine organisms, (2016).

[17] L. Van Cauwenberghe, L. Devriese, F. Galgani, J. Robbens, C.R. Janssen, Microplastics in sediments: A review of techniques, occurrence and effects, Mar. Environ. Res. 111 (2015) 5-17. doi:10.1016/j.marenvres.2015.06.007.

[18] D.K.A. Barnes, F. Galgani, R.C. Thompson, M. Barlaz, Accumulation and fragmentation of plastic debris in global environments, Philos. Trans. R. Soc. B Biol. Sci. 364 (2009) 1985-1998. doi:10.1098/rstb.2008.0205.

[19] M.A. Browne, P. Crump, S.J. Niven, E. Teuten, A. Tonkin, T. Galloway, R. Thompson, Accumulation of microplastic on shorelines woldwide: Sources and sinks, Environ. Sci. Technol. 45 (2011) 9175-9179. doi:10.1021/es201811s.

[20] C.C. Ebbesmeyer, W.J. Ingraham, T.C. Royer, C.E. Grosch, Tub Toys Orbit the Pacific Subarctic Gyre, Eos, Trans. Am. Geophys. Union. 88 (2007) 1. doi:10.1029/2007EO010001.

[21] M. Thiel, I.A. Hinojosa, L. Miranda, J.F. Pantoja, M.M. Rivadeneira, N. Vásquez, Anthropogenic marine debris in the coastal environment: A multi-year comparison between coastal waters and local shores, Mar. Pollut. Bull. 71 (2013) 307-316. 
doi:10.1016/j.marpolbul.2013.01.005.

[22] UNEP, Marine Litter: A Global Challenge, 2009.

[23] D. Haynes, Marine debris on continental islands and sand cays in the Far Northern Section of the Great Barrier Reef Marine Park, Australia, Mar. Pollut. Bull. 34 (1997) 276-279. doi:10.1016/S0025-326X(96)00179-8.

[24] P. Convey, D.K.A. Barnes, A. Morton, Debris accumulation on oceanic island shores of the Scotia Arc, Antarctica, Polar Biol. 25 (2002) 612-617. doi:10.1007/s00300-002-0391$\mathrm{x}$.

[25] J.L. Lavers, A.L. Bond, Exceptional and rapid accumulation of anthropogenic debris on one of the world' s most remote and pristine islands, 114 (2017) 6052-6055. doi:10.1073/pnas.1619818114.

[26] NOAA and UNEP, The Honolulu Strategy: A Global Framework for Prevention and Management of Marine Debris, A Rep. Dev. by United Nations Environ. Program. Natl. Ocean. Atmos. Adm. Mar. Debris Progr. Fifth Int. Mar. Debris Conf. (2011) 1-50. doi:10.1017/CBO9781107415324.004.

[27] S. Ramachandran, S. Anitha, V. Balamurugan, K. Dharanirajan, K. Ezhil Vendhan, M.I.P. Divien, A. Senthil Vel, I. Sujjahad Hussain, A. Udayaraj, Ecological impact of tsunami on Nicobar Islands (Camorta, Katchal, Nancowry and Trinkat), Curr. Sci. 89 (2005) 195200.

[28] T. Shimizu, J. Nakai, K. Nakajima, N. Kozai, G. Takahashi, M. Matsumoto, J. Kikui, Seasonal variations in coastal debris on Awaji Island, Japan, Mar. Pollut. Bull. 57 (2008) 182-186. doi:10.1016/j.marpolbul.2007.10.005. 
[29] S.L. Moore, D. Gregorio, M. Carreon, S.B. Weisberg, M.K. Leecaster, Composition and distribution of beach Debris in Orange County, California, Mar. Pollut. Bull. 42 (2001) 241-245. doi:10.1016/S0025-326X(00)00148-X.

[30] M.R. Claereboudt, Shore litter along sandy beaches of the Gulf of Oman, Mar. Pollut. Bull. 49 (2004) 770-777. doi:10.1016/j.marpolbul.2004.06.004.

[31] L. Martinez-ribes, G. Basterretxea, M. Palmer, J. Tintoré, Origin and abundance of beach debris in the Balearic Islands, 71 (2007) 305-314.

[32] M. Bravo, M. de los Ángeles Gallardo, G. Luna-Jorquera, P. Núñez, N. Vásquez, M. Thiel, Anthropogenic debris on beaches in the SE Pacific (Chile): Results from a national survey supported by volunteers, Mar. Pollut. Bull. 58 (2009) 1718-1726. doi:10.1016/j.marpolbul.2009.06.017.

[33] J. Lee, S. Hong, Y.K. Song, S.H. Hong, Y.C. Jang, M. Jang, N.W. Heo, G.M. Han, M.J. Lee, D. Kang, W.J. Shim, Relationships among the abundances of plastic debris in different size classes on beaches in South Korea, Mar. Pollut. Bull. 77 (2013) 349-354. doi:10.1016/j.marpolbul.2013.08.013.

[34] R. Andrades, A.S. Martins, L.M. Fardim, J.S. Ferreira, R.G. Santos, Origin of marine debris is related to disposable packs of ultra-processed food, MPB. 109 (2016) 192-195. doi:10.1016/j.marpolbul.2016.05.083.

[35] E. Hengstmann, D. Gräwe, M. Tamminga, E. Kerstin, Marine litter abundance and distribution on beaches on the Isle of Rügen considering the in fl uence of exposition, morphology and recreational activities, Mar. Pollut. Bull. 115 (2017) 297-306. doi:10.1016/j.marpolbul.2016.12.026. 
[36] A.J.R. Watts, A. Porter, N. Hembrow, J. Sharpe, T.S. Galloway, C. Lewis, Through the sands of time : Beach litter trends from nine cleaned north cornish beaches *, Environ. Pollut. 228 (2017) 416-424. doi:10.1016/j.envpol.2017.05.016.

[37] B.J.L. Laglbauer, R.M. Franco-santos, M. Andreu-cazenave, L. Brunelli, M. Papadatou, A. Palatinus, M. Grego, T. Deprez, Macrodebris and microplastics from beaches in Slovenia, Mar. Pollut. Bull. 89 (2014) 356-366. doi:10.1016/j.marpolbul.2014.09.036.

[38] OSPAR, Guideline for monitoring marine litter on the beaches in the OSPAR maritime area, OSPAR Comm. London, 84pp. (2010).

[39] A. Cheshire, E. Adler, J. Barbière, Y. Cohen, UNEP/IOC Guidelines on survey and monitoring of marine litter, 2009.

[40] P.G. Ryan, C.J. Moore, J.A. van Franeker, C.L. Moloney, Monitoring the abundance of plastic debris in the marine environment, Philos. Trans. R. Soc. B Biol. Sci. 364 (2009) 1999-2012. doi:10.1098/rstb.2008.0207.

[41] M. Schulz, W. van Loon, D.M. Fleet, P. Baggelaar, E. van der Meulen, OSPAR standard method and software for statistical analysis of beach litter data, Mar. Pollut. Bull. 122 (2017) 166-175. doi:10.1016/j.marpolbul.2017.06.045.

[42] S.E. Nelms, C. Coombes, L.C. Foster, T.S. Galloway, B.J. Godley, P.K. Lindeque, M.J. Witt, Science of the Total Environment Marine anthropogenic litter on British beaches : A 10-year nationwide assessment using citizen science data, Sci. Total Environ. 579 (2017) 1399-1409. doi:10.1016/j.scitotenv.2016.11.137.

[43] J.L. Lavers, S. Oppel, A.L. Bond, Factors influencing the detection of beach plastic debris, Mar. Environ. Res. 119 (2016) 245-251. doi:10.1016/j.marenvres.2016.06.009. 
[44] N. Abdo, A. Al-shwa, A. Mohsen, Litter on the Beaches of the Red Sea of Yemen, 81 (2011) 2717-2723. doi:10.1134/S1070363211130135.

[45] A.H. Abu-hilal, Litter pollution on the Jordanian shores of the Gulf of Aqaba ( Red Sea), 58 (2004) 39-63. doi:10.1016/j.marenvres.2003.12.003.

[46] A. Bhardwaj, L. Sam, Akanksha, F.J. Martín-Torres, R. Kumar, UAVs as remote sensing platform in glaciology: Present applications and future prospects, Remote Sens. Environ. 175 (2016) 196-204. doi:10.1016/j.rse.2015.12.029.

[47] A.M. Cunliffe, R.E. Brazier, K. Anderson, Ultra-fine grain landscape-scale quantification of dryland vegetation structure with drone-acquired structure-from-motion photogrammetry, Remote Sens. Environ. 183 (2016) 129-143. doi:10.1016/j.rse.2016.05.019.

[48] G.P. Jones, L.G. Pearlstine, H.F. Percival, An Assessment of Small Unmanned Aerial Vehicles for Wildlife Research, Wildl. Soc. Bull. 34 (2006) 750-758. doi:10.2193/00917648(2006)34[750:AAOSUA]2.0.CO;2.

[49] A. Hodgson, N. Kelly, D. Peel, Unmanned Aerial Vehicles ( UAVs ) for Surveying Marine Fauna : A Dugong Case Study, 8 (2013) 1-15. doi:10.1371/journal.pone.0079556.

[50] L.J.P.\& P.M.B. Elizabeth Bevan1, Thane Wibbels1, Blanca M.Z. Najera2, Marco A.C. Martinez2, Laura A.S. Martinez2, Francisco I. Martinez3, 4, Javier M. Cuevas3, 4, Tiffany Anderson3, Amy Bonka1, Mauricio H. Hernandez3, Unmanned Aerial Vehicles (UAVs) for Monitoring Sea Turtles in Near-Shore Waters, Mar. Turt. Newsl. (2015) 1922. doi:0839-7708.

[51] J.C. Hodgson, S.M. Baylis, R. Mott, A. Herrod, R.H. Clarke, Precision wildlife 
monitoring using unmanned aerial vehicles, Sci. Rep. 6 (2016). doi:10.1038/srep22574.

[52] M.F. McCabe, M. Rodell, D.E. Alsdorf, D.G. Miralles, R. Uijlenhoet, W. Wagner, A. Lucieer, R. Houborg, N.E.C. Verhoest, T.E. Franz, J. Shi, H. Gao, E.F. Wood, The future of Earth observation in hydrology, Hydrol. Earth Syst. Sci. 21 (2017) 3879-3914. doi:10.5194/hess-21-3879-2017.

[53] A. Papakonstantinou, K. Topouzelis, G. Pavlogeorgatos, Coastline Zones Identification and 3D Coastal Mapping Using UAV Spatial Data, ISPRS Int. J. Geo-Information. 5 (2016) 75. doi:10.3390/ijgi5060075.

[54] E. Casella, A. Rovere, A. Pedroncini, C.P. Stark, M. Casella, M. Ferrari, M. Firpo, Drones as tools for monitoring beach topography changes in the Ligurian Sea (NW Mediterranean), Geo-Marine Lett. 36 (2016) 151-163. doi:10.1007/s00367-016-0435-9.

[55] I.L. Turner, M.D. Harley, C.D. Drummond, UAVs for coastal surveying, Coast. Eng. 114 (2016) 19-24. doi:10.1016/j.coastaleng.2016.03.011.

[56] S. Brosse, S. Lek, C.R. Townsend, Abundance, diversity, and structure of freshwater invertebrates and fish communities: an artificial neural network approach, New Zeal. J. Mar. Freshw. Res. 35 (2001) 135-145. doi:10.1080/00288330.2001.9516983.

[57] M.G. Rollins, R.E. Keane, R.A. Parsons, Mapping fuels and fire regimes using remote sensing, ecosystem simulation, and gradient modeling, Ecol. Appl. 14 (2004) 75-95. doi:10.1890/02-5145.

[58] J.D. Olden, M.K. Joy, R.G. Death, Rediscovering the species in community-wide predictive modeling, Ecol. Appl. 16 (2006) 1449-1460. doi:10.1890/10510761(2006)016[1449:RTSICP]2.0.CO;2. 
[59] L.R. Iverson, A.M. Prasad, Using landscape analysis to assess and model tsunami damage in Aceh province, Sumatra, Landsc. Ecol. 22 (2007) 323-331. doi:10.1007/s10980-0069062-6.

[60] D. Li, C. Tang, C. Xia, H. Zhang, Acoustic mapping and classification of benthic habitat using unsupervised learning in artificial reef water, Estuar. Coast. Shelf Sci. 185 (2017) 11-21. doi:10.1016/j.ecss.2016.12.001.

[61] N. Dalal, B. Triggs, Histograms of oriented gradients for human detection, in: Proc. - 2005 IEEE Comput. Soc. Conf. Comput. Vis. Pattern Recognition, CVPR 2005, 2005: pp. 886893. doi:10.1109/CVPR.2005.177.

[62] C. Cortes, V. Vapnik, Support-Vector Networks, Mach. Learn. 20 (1995) 273-297. doi:10.1023/A:1022627411411.

[63] C. Zhang, C. Liu, X. Zhang, G. Almpanidis, An up-to-date comparison of state-of-the-art classification algorithms, Expert Syst. Appl. 82 (2017) 128-150. doi:10.1016/j.eswa.2017.04.003.

[64] I. Arel, D.C. Rose, T.P. Karnowski, Deep Machine Learning - A New Frontier in Artificial Intelligence Research, IEEE Comput. Intell. Mag. 5 (2010) 13-18. doi:10.1109/MCI.2010.938364. 
Table 1 Main anthropogenic debris categories observed during fieldwork and used to classify debris found during visual census and manual processing of UAV images. For each category, a description and examples are provided.

\begin{tabular}{ll}
\hline Debris Categories & Description \\
\hline Drink bottles & $\begin{array}{l}\text { Plastic and glass bottles for beverages (e.g. water bottles, soft drinks bottles, juices } \\
\text { bottles, etc.) up to } 3 \mathrm{~L} \text { volume. }\end{array}$ \\
Drink drums & $\begin{array}{l}\text { Plastic dispensers, drums and bottles for water from 3 L volume. } \\
\text { Plastic caps for bottles and dispens ers. Caps diameters are gen erally comprised between }\end{array}$ \\
Bottle caps & $\begin{array}{l}2.5 \text { and } 6 \mathrm{~cm} . \\
\text { Plastic bags }\end{array}$ \\
Plastic bags for shopping, garbage and freezer. \\
Oil containers & Plastic bottles, containers and drums for petrol and engine oil from 0.5 L volume. \\
Detergent and other & Plastic bottles, containers and drums for cleaners, deterg ents, cosmetics (e.g. bleach, \\
liquids containers & soap, shampoo, etc.). \\
Ropes & Fishing ropes of more than 0.2 cm diameter. \\
Footwear & Any footwear (e.g. shoes, sandals, flip flops, boots, etc.) \\
Boxes-crates-baskets & $\begin{array}{l}\text { Plastic containers (e.g. boxes, crates, baskets, buckets, polystyrene boxes, etc.). } \\
\text { Any other less represented debris of any material (i.e. plastic, glass, aluminum and } \\
\text { tetrapak). It includes plastic fragments, cans, food containers and wraps, cups, bulbs, } \\
\text { nets, buoys, fishing lines, clothes, unidentified items, etc. }\end{array}$ \\
\hline
\end{tabular}

Table 2 Results from manual screening of the test beach orthomosaic: abundance ( $\mathrm{n}$ of items), density (items. $\mathrm{m}^{-2}$ ) and relative proportion (\%) of 10 debris categories as in Fig. 3.

\begin{tabular}{lrrr}
\hline Debris Categories & Abundance (n items) & Density (items. $\mathrm{m}^{-2}$ ) & Proportion (\%) \\
\hline Drink bottles & 738 & 0.12 & 42 \\
Drink drums & 45 & 0.007 & 2.6 \\
Bottle caps & 46 & 0.007 & 2.6 \\
Plastic bags & 80 & 0.013 & 4.6 \\
Oil containers & 38 & 0.006 & 2.2 \\
Detergent and other liquids & 36 & 0.006 & 2.1 \\
containers & 24 & 0.004 & 1.4 \\
Ropes & 24 & 0.004 & 1.4 \\
Footwear & 20 & 0.003 & 1.1 \\
Boxes-crates-baskets & 705 & 0.11 & 40 \\
Others & & & \\
\hline
\end{tabular}


Table 3 Comparison of results obtained from two monitoring methods on an area of $56 \mathrm{~m}^{2}$ : visual census and remote survey followed by manual screening of aerial pictures. Each method section reports abundance (n of items) and relative proportion (\%) of the categories detected. Seven main categories were identified in the area surveyed.

\begin{tabular}{lrr|rr}
\hline \multicolumn{2}{c}{ Visual Census } & \multicolumn{2}{c}{$\begin{array}{c}\text { Remote Survey } \\
\text { + Manual Screening }\end{array}$} \\
\hline Debris Categories & Abundance & Proportion & Abundance & Proportion \\
\hline Drink bottles & $\mathbf{4 5}$ & $\mathbf{3 6 . 6 \%}$ & $\mathbf{2 8}$ & $\mathbf{3 6 . 8 \%}$ \\
$\quad$ of which glass bottles & 4 & $3.2 \%$ & 2 & $2.6 \%$ \\
Bottle caps & $\mathbf{1 4}$ & $\mathbf{1 1 . 4 \%}$ & $\mathbf{1}$ & $\mathbf{1 . 3 \%}$ \\
Plastic bags & $\mathbf{8}$ & $\mathbf{6 . 5 \%}$ & $\mathbf{1}$ & $\mathbf{1 . 3 \%}$ \\
Oil and detergent & $\mathbf{1 0}$ & $\mathbf{8 . 1 \%}$ & $\mathbf{1 2}$ & $\mathbf{1 5 . 8 \%}$ \\
containers & $\mathbf{4}$ & $\mathbf{3 . 2 \%}$ & $\mathbf{2}$ & $\mathbf{2 . 6 \%}$ \\
Ropes & $\mathbf{2}$ & $\mathbf{1 . 6 \%}$ & $\mathbf{2}$ & $\mathbf{2 . 6 \%}$ \\
Footwear & $\mathbf{4 0}$ & $\mathbf{3 2 . 5 \%}$ & $\mathbf{3 0}$ & $\mathbf{3 9 . 5 \%}$ \\
Others & 2 & $1.6 \%$ & 2 & $2.6 \%$ \\
$\quad$ Neon lamps & 2 & $1.6 \%$ & 1 & $1.3 \%$ \\
Cans & 2 & $1.6 \%$ & 1 & $1.3 \%$ \\
Cups & 2 & $1.6 \%$ & 0 & $0 \%$ \\
Bullets & 1 & $0.8 \%$ & 1 & $1.3 \%$ \\
Deodorant stick & 1 & $0.8 \%$ & 0 & $0 \%$ \\
Food wrap & 1 & $0.8 \%$ & 0 & $0 \%$ \\
Toothpaste & 1 & $0.8 \%$ & 0 & $0 \%$ \\
Toothbrush & 1 & $0.8 \%$ & 0 & $0 \%$ \\
Straw & 6 & $4.9 \%$ & 5 & $6.5 \%$ \\
Pipes & 3 & $2.4 \%$ & 0 & $0 \%$ \\
Plastic rings (from bottle caps) & 1 & $0.8 \%$ & 1 & $1.3 \%$ \\
Big plastic fragments & $17.8 \% \%$ & 0 & $0 \%$ \\
Small plastic fragments & 0 & $0 \%$ & 19 & $25 \%$ \\
\hline Unidentified items & & & &
\end{tabular}


Table 4 Comparison of results obtained from manual and automatic processing through machine learning of 13 aerial pictures: total abundance ( $\mathrm{n}$ items), mean abundance \pm SE in each picture (n items) and mean proportion \pm SE (\%). Last column shows Mann-Whitney statistic value (W) and p-value ( $p$ ) of comparisons between median proportions obtained from the two approaches.

\begin{tabular}{l|rrr|rrr|r}
\hline & \multicolumn{4}{|c|}{ Manual Processing } & \multicolumn{4}{c|}{ Machine Learning } \\
\hline $\begin{array}{l}\text { Debris } \\
\text { Categories }\end{array}$ & $\begin{array}{r}\text { Total } \\
\text { abundance } \\
\text { (n items) }\end{array}$ & $\begin{array}{r}\text { Mean abundance } \\
\pm \text { SE (n items per } \\
\text { picture) }\end{array}$ & $\begin{array}{r}\text { Mean proportion } \\
\pm \text { SE (\% per } \\
\text { picture) }\end{array}$ & $\begin{array}{r}\text { Total } \\
\text { abundance } \\
\text { (n items) }\end{array}$ & $\begin{array}{r}\text { Mean abundance } \\
\pm S E(n \text { items per } \\
\text { picture) }\end{array}$ & $\begin{array}{r}\text { Mean proportion } \\
\pm S E ~(\% \text { per } \\
\text { picture) }\end{array}$ & $\begin{array}{r}\text { Mann-Whitney } \\
\text { test comparisons }\end{array}$ \\
\hline $\begin{array}{l}\text { Drink } \\
\text { containers }\end{array}$ & 367 & $28.23 \pm 5.14$ & $85.3 \pm 4$ & 1912 & $147.1 \pm 21.19$ & $91.4 \pm 0.8$ & $\mathrm{~W}=157 ; \mathrm{p}=0.356$ \\
Bottle caps & 20 & $1.54 \pm 0.39$ & $4.5 \pm 1.1$ & 120 & $9.23 \pm 2.49$ & $4.5 \pm 0.8$ & $\mathrm{~W}=176 ; \mathrm{p}=1$ \\
Plastic bags & 26 & $2 \pm 0.51$ & $10.2 \pm 3.3$ & 71 & $5.46 \pm 0.6$ & $4.1 \pm 0.8$ & $\mathrm{~W}=206 ; \mathrm{p}=0.124$ \\
\hline
\end{tabular}

Table 5 Visual census results on 9 sites: mean density (items. $\mathrm{m}^{-2}$ ) $\pm \mathrm{SE}$ and mean relative proportion (\%) \pm SE of 10 debris categories as in Fig. 3 .

\begin{tabular}{lll}
\hline Debris Categories & Density (mean items. $\left.{ }^{-2} \pm \mathrm{SE}\right)$ & Proportion $($ mean $\% \pm \mathrm{SE})$ \\
\hline Drink bottles & $0.25 \pm 0.31$ & $42.5 \pm 4.7$ \\
Drink drums & $0.007 \pm 0.02$ & $1.3 \pm 0.2$ \\
Bottle caps & $0.035 \pm 0.09$ & $4.6 \pm 1$ \\
Plastic bags & $0.025 \pm 0.03$ & $5.9 \pm 4.6$ \\
Oil containers & $0.057 \pm 0.12$ & $8.6 \pm 2.1$ \\
Detergent and other liquids & $0.017 \pm 0.3$ & $2.4 \pm 0.4$ \\
containers & $0.018 \pm 0.05$ & $3 \pm 0.6$ \\
Ropes & $0.007 \pm 0.03$ & $1 \pm 0.4$ \\
Footwear & $0.003 \pm 0.01$ & $0.5 \pm 0.2$ \\
Boxes-crates-baskets & $0.19 \pm 0.06$ & $30.2 \pm 3.7$ \\
Others & & \\
\hline
\end{tabular}




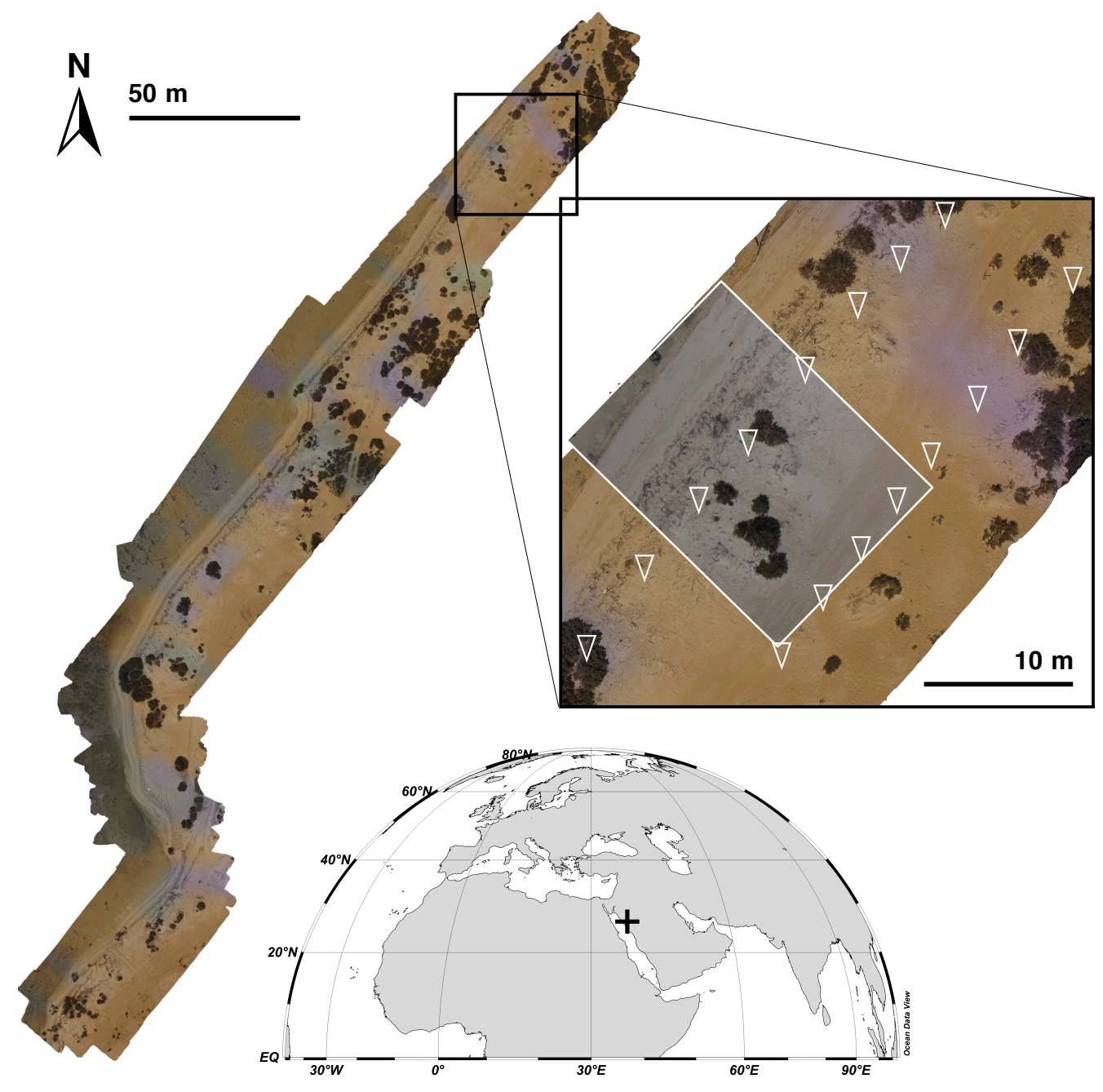

Fig. 1 Study site. Geographic location of the test beach (black cross on the world map) and area surveyed with the UAV, represented in this figure by the orthomosaic obtained merging 243 aerial pictures. The orthomosaic close-up shows (with white marks) the distribution of 16 aerial pictures, like the one framed in white. A .kmz file of the orthomosaic is also provided. 


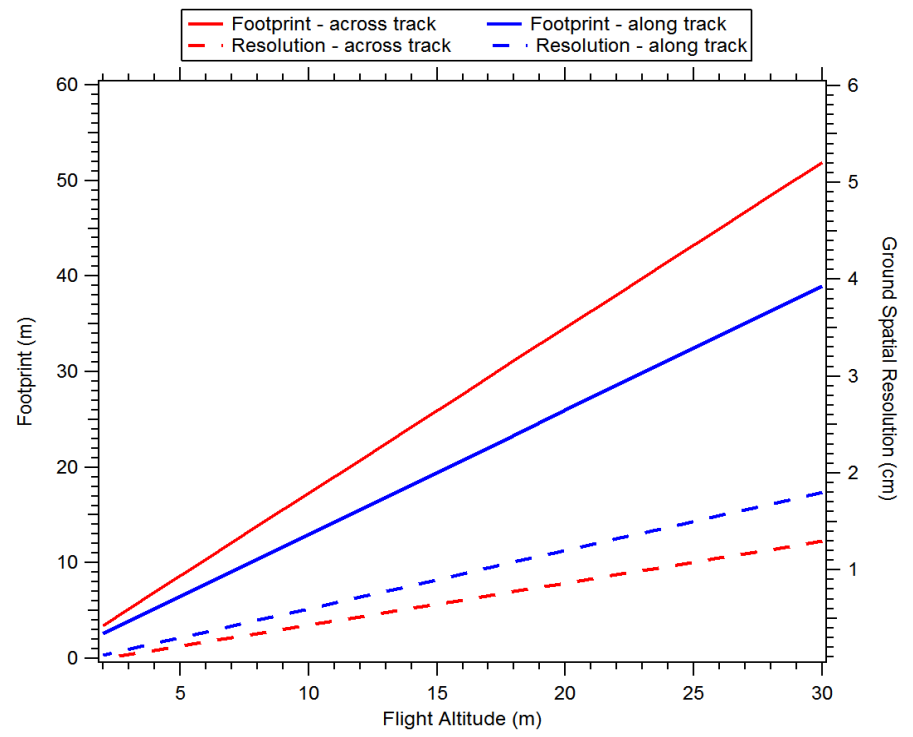

Fig. 2 Footprint and ground resolution across and along track related to flight altitude for a 12 MP camera. Ground resolution is calculated on a camera angle of $90^{\circ}$ to the floor. 
A

(1)

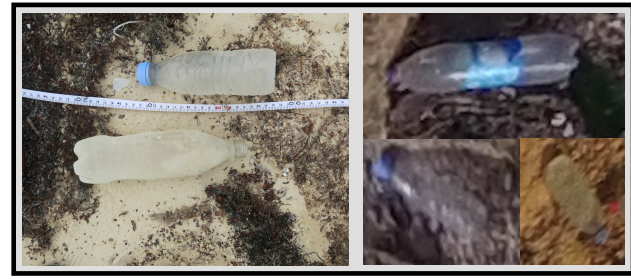

(2)

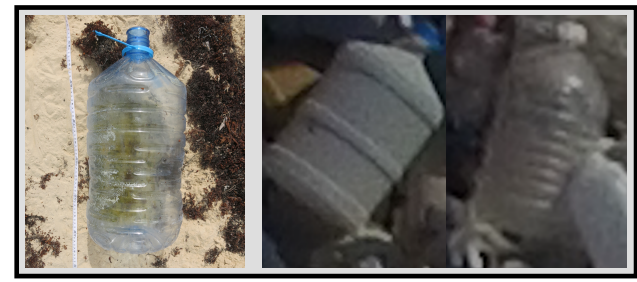

B

(5)

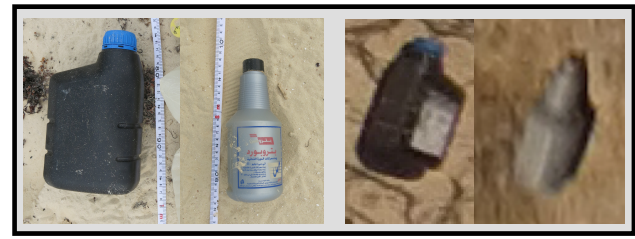

(6)

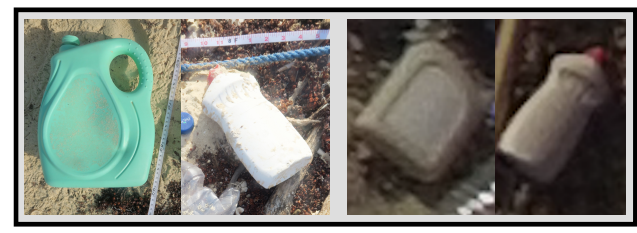

(7)

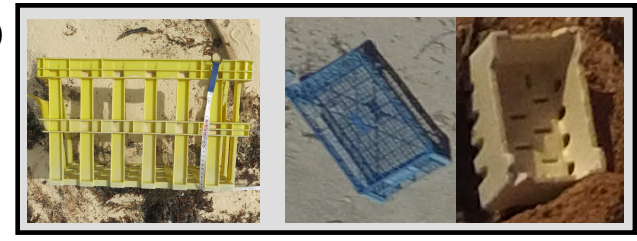

(3)

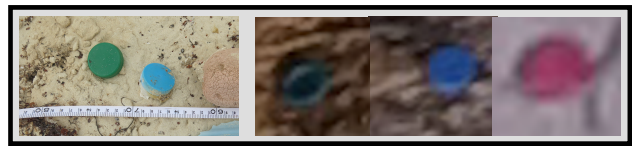

(4)

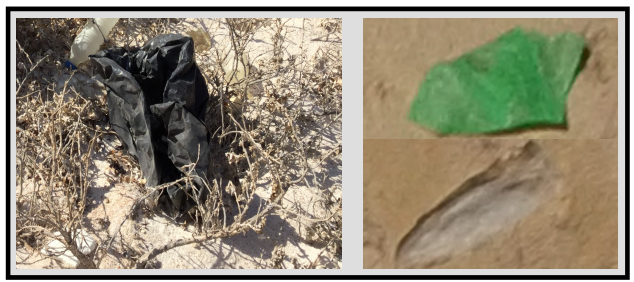

(8)

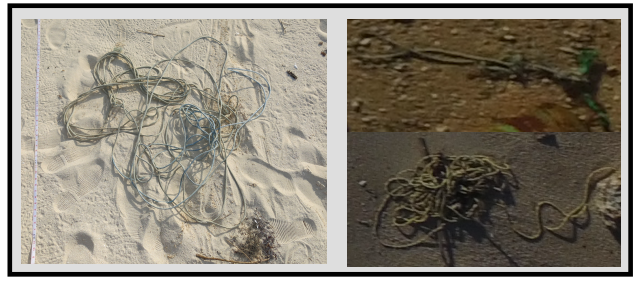

(9)

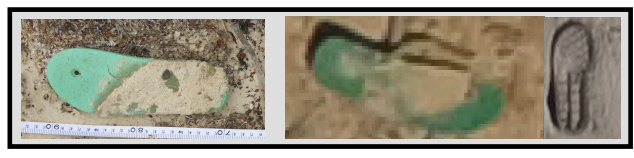

(10)

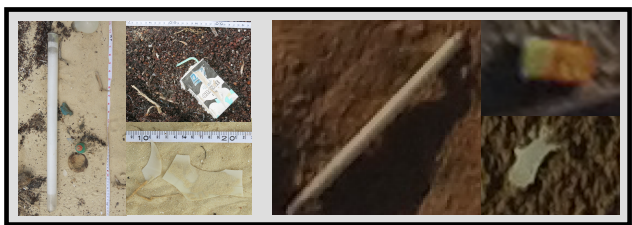

Fig. 3 Example pictures of the main anthropogenic debris categories observed during fieldwork. Each frame represents one category: pictures on the left are taken from land, on the right through UAV flown at 10-m altitude. A) Debris categories recognized by multi-class random forest: "drink bottles" (1) and "drink drums" (2) merged in the category "drink containers"; "bottle caps" (3) and "plastic bags" (4). B) Additional categories used for classification during visual census and manual processing of UAV images: "oil containers" (5); "detergent and other liquids containers" (6); "boxes-crates-baskets" (7); "ropes" (8); "footwear" (9) and "others". The latter includes items rarely encountered (e.g. lamps, bricks in Tetra Pak) and fragments or, when monitored through remote survey, without a recognizable and unique shape but with features such regular borders and bright colors that define their anthropological origin (e.g. half buried items or unidentified items). 


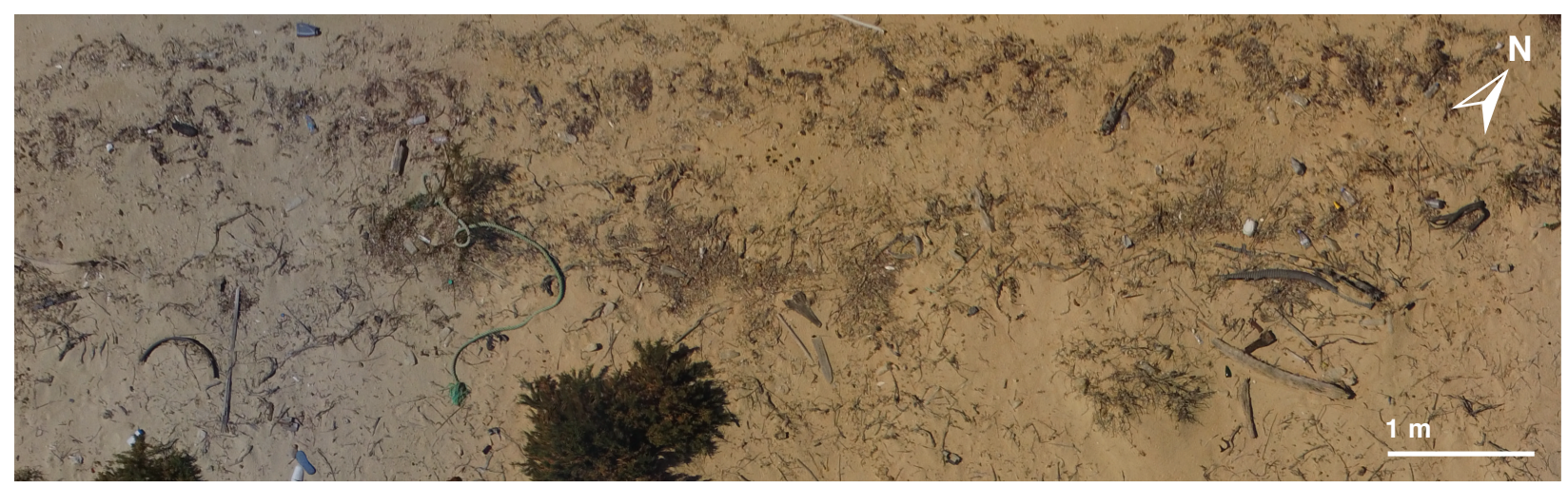

Fig. 4 Beach area, 14-m long and 4-m wide, used for ground assessment viewed from a 10-m altitude. 


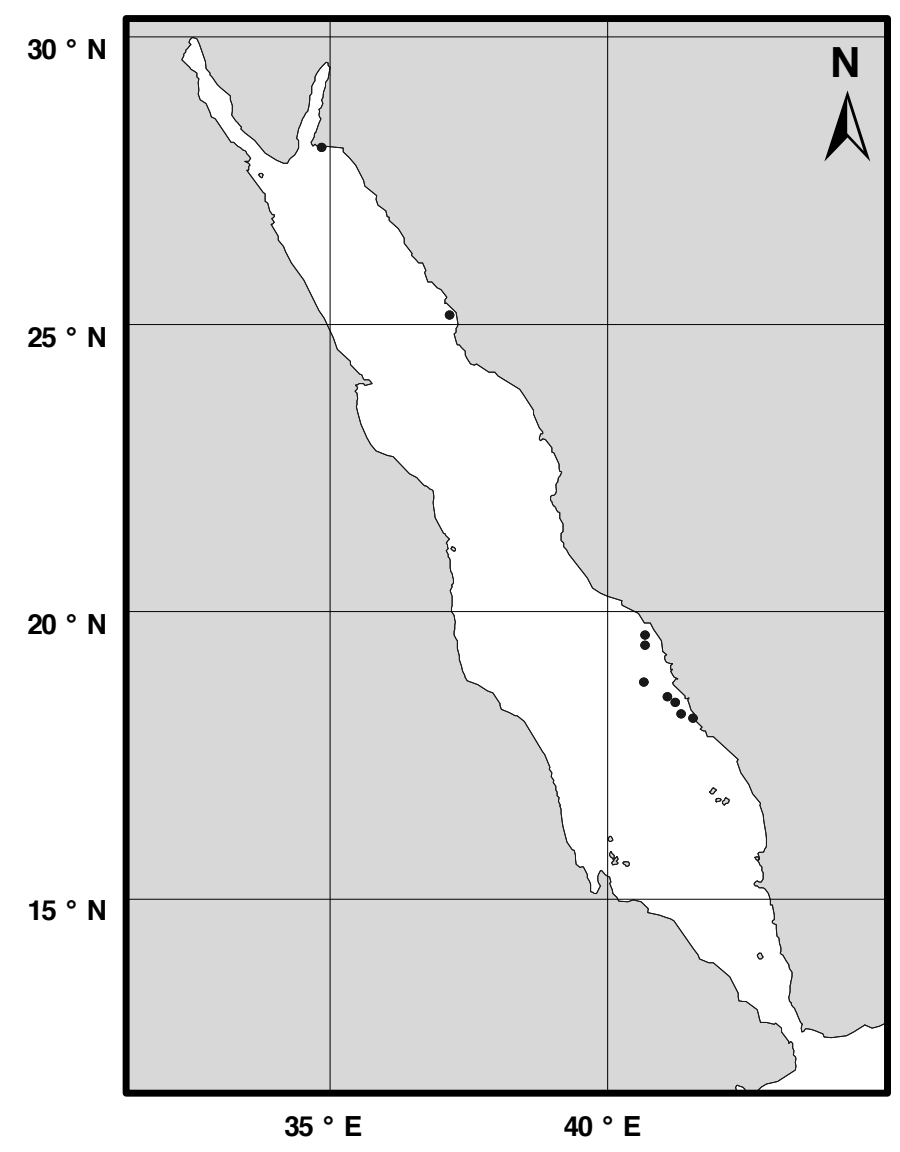

Fig. 5 Sites map of visual census surveys. Black dots correspond to 9 sites surveyed through visual census, at each site plastic was counted along 6 to 18 transects 5 - to 50-m long. 


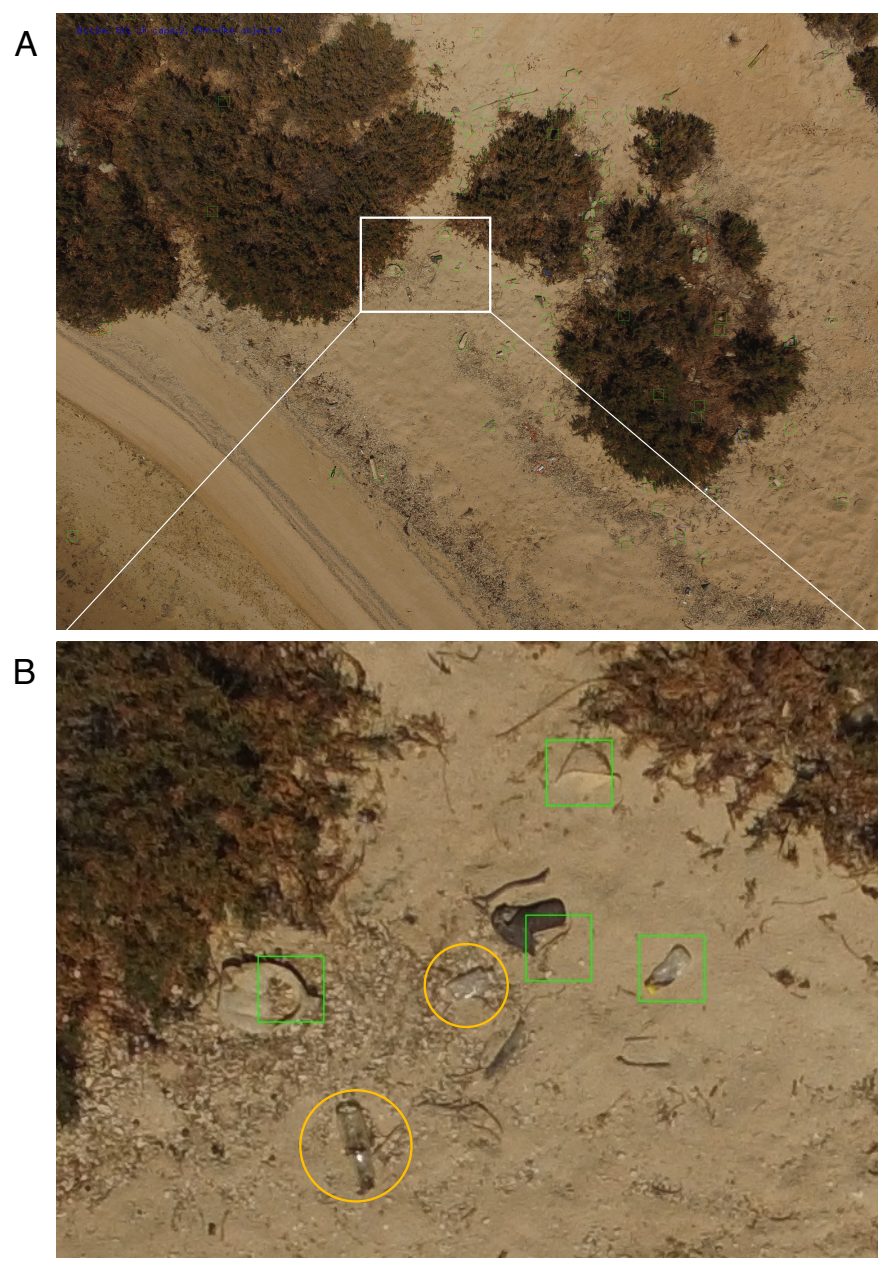

Fig. 6 A) Example of random forest classification on one aerial picture. Quadrats represent object detected by the random forest: "drink containers" in green; "bottle caps" in red and "plastic bags" in blue. B) Close-up of the aerial picture corresponding to the white area in A). In this zoom, 4 objects were detected as "drink containers": 3 are correctly classified (a bottle, a half-buried bottle and a drum) and 1 is a false positive (a wooden stick). Two bottles were missed detected (in yellow). 
KMZ file of the beach orthomosaic in Fig. 1
Click here to download Interactive Map file (.kml or .kmz): Orthomosaic.kmz

KMZ file of the beach orthomosaic in Fig. 1
Click here to download Interactive Map file (.kml or .kmz): Orthomosaic.kmz 